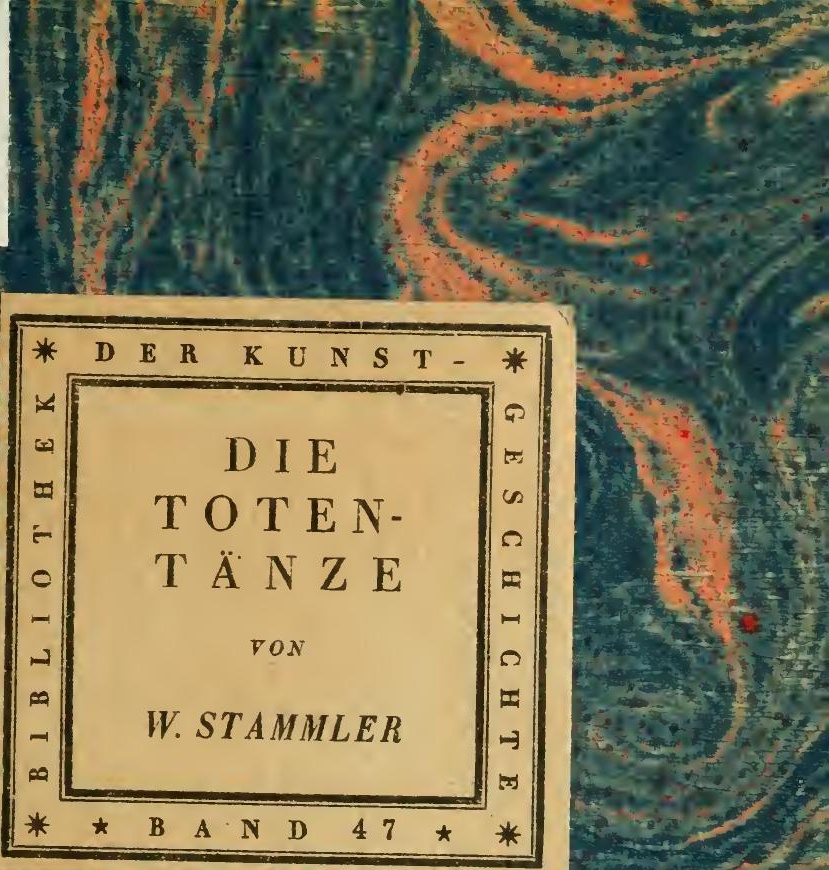

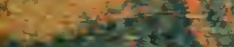

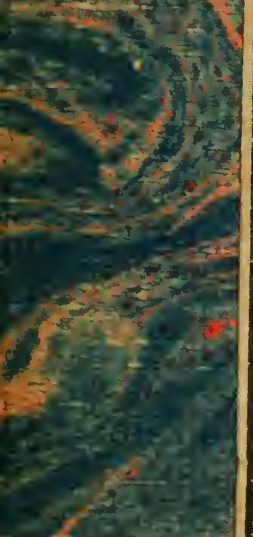

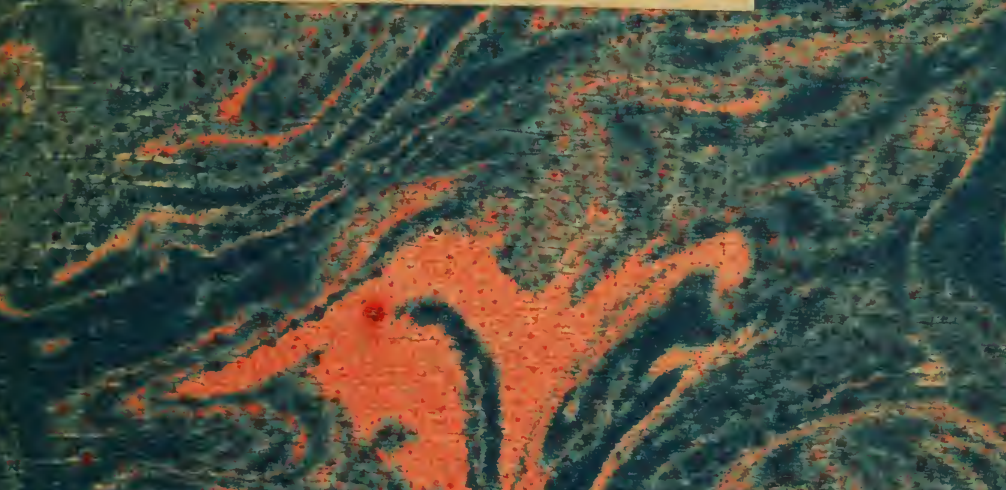

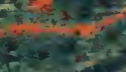

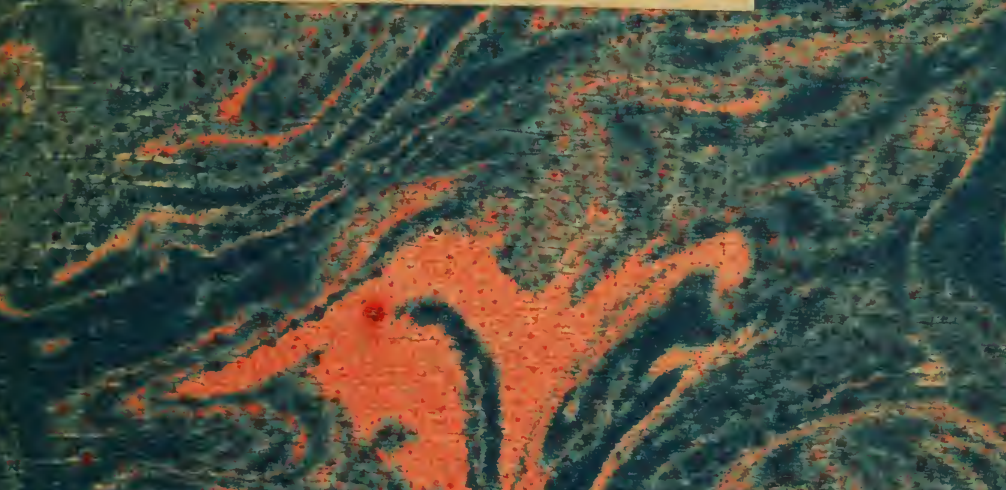
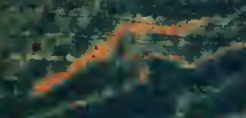

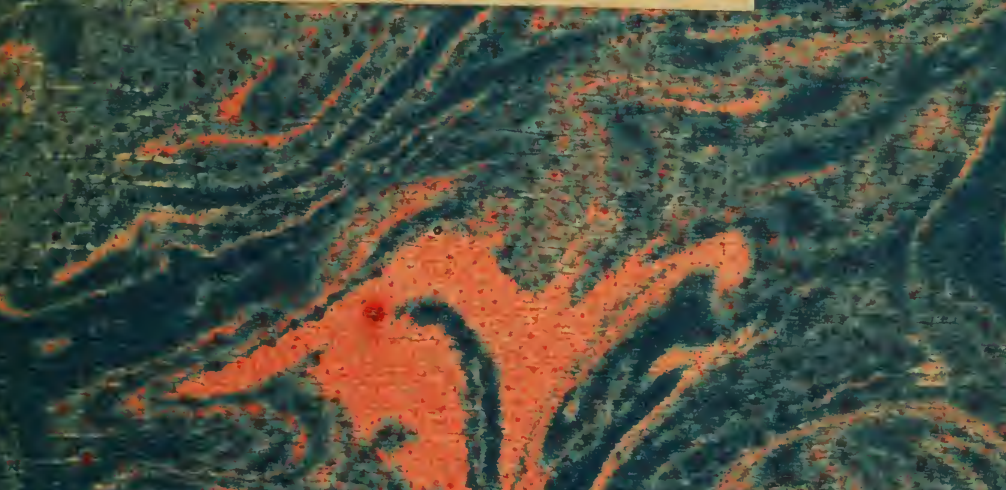

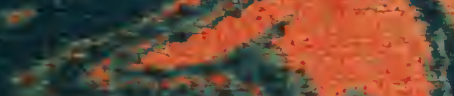

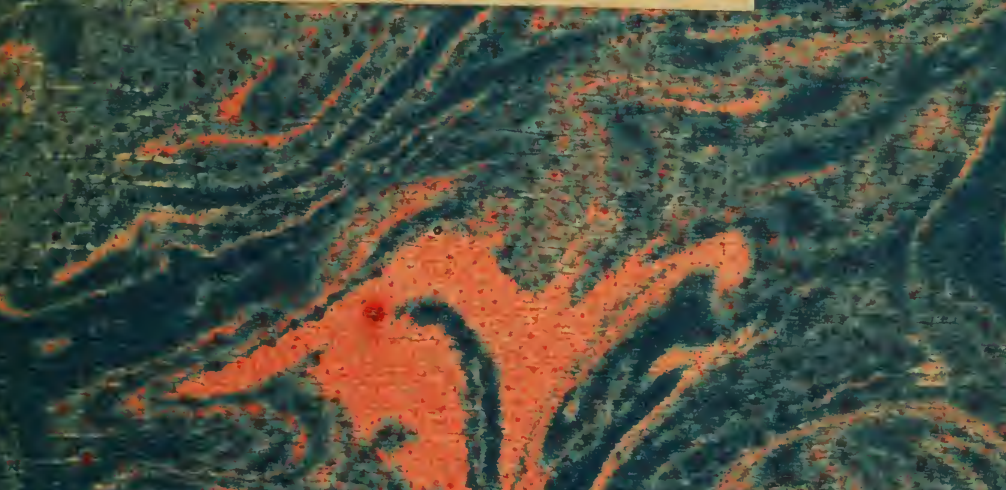

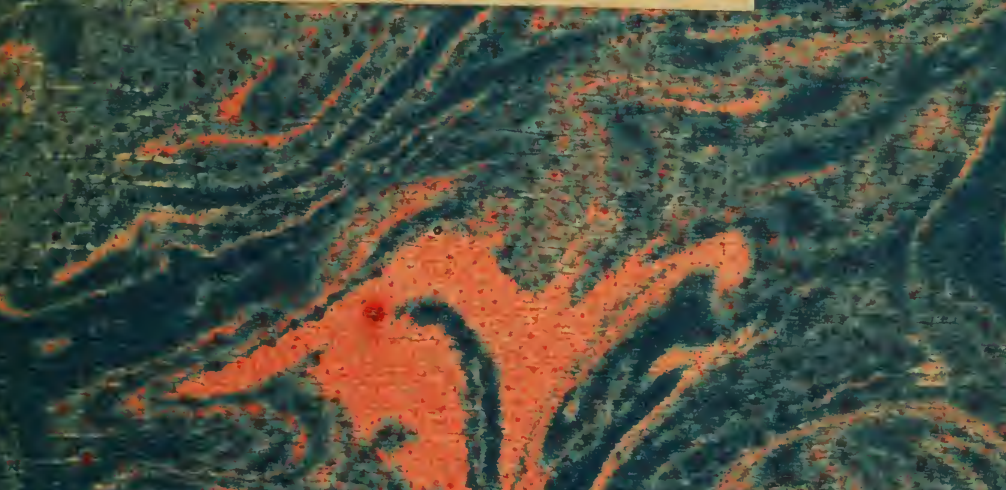
(3)

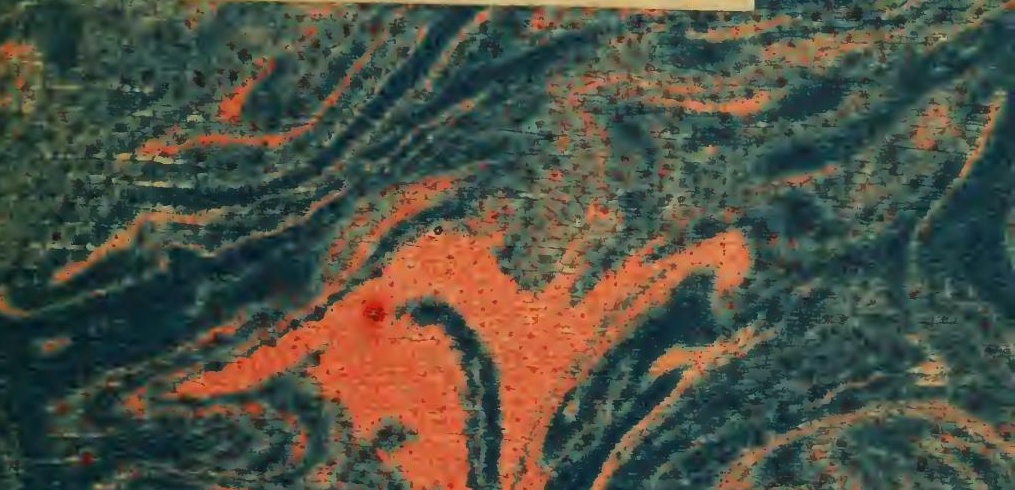

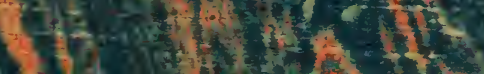

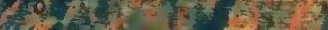




D I E T O T E N T Ä N Z E VON

\section{WOLFGANG STAMMLER}

\section{E I P Z I G}

\section{VERLAG VON E.A. SEEMANN}



B I B L I O T H E K

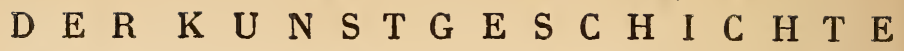
HERAUSGEGEBEN VON HANS TIETZE

$$
\text { B A N D } 47
$$

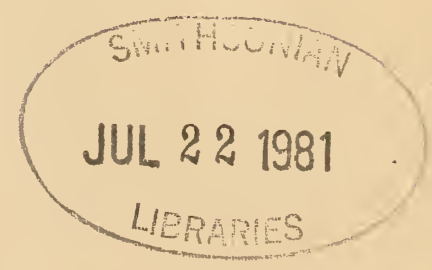

Copyright by E. A. Seemann, Loipzig 1922

Druck von Ernst Hedrich Nachf., Leipzig - Ätzungen von Kirstein \& Co., Leipzig 
Wedia vita in morte sumus!" Diese Worte des , 1 St. Galler Dichtermönches Notkers des Stammlers trug der mittelalterliche Mensch alle Zeit im Herzen und bemühte sich, danach sein Leben einzurichten. Da er jeden Augenblick sterben konnte, mußte er seinem Gott eine möglichst sündenlose Seele darbringen, wenn von ihm im Jenseits Rechenschaft gefordert wurde. Der gläubige Christ machte sich also durch ein frommes Leben, durch gute Taten, Wallfahrten, Almosen bereit, ein gnädiges Urteil nach dem Tode zu erhalten.

In Frankreich war seit der Mitte des 13. Jahrhunderts ein ungemein starkes religiöses und kirchliches Bewußtsein vorhanden. Das Mönchtum hatte sich blühend entwickelt, Bernhard von Clairvaux und Hugo von St. Victor waren hervorragende Anreger in Wort und Schrift gewesen, die Bettelorden faßten rasch festen $\mathrm{FuB}$, die Albigenserkriege wurden mit derselben Begeisterung geführt wie die Kreuzzüge. Allenthalben taucht nun im Mittelalter und in der Neuzeit der Glaube auf, daß die Toten nachts auf den Friedhöfen Tänze aufführen; sie suchen die Lebenden in ihren Reigen hineinzuziehen, und wer ihn mitspringt, ist ihnen verfallen: er stirbt entweder auf der Stelle oder siecht einem sicheren Tode entgegen. Aus dem religiösen Untergrund Frankreichs erwuchs zuerst der Gedanke, den Reigen der Toten und der Lebenden bildlich darzustellen, verbunden mit dem ebenfalls in der mittelalterlichen Literatur bereits früh vorkommenden Motiv der Ständesatire und gedacht als ein Memento mori: daß die Toten jederzeit den Sünder holen können, und

B. D. K. 47 
dieser sich daher rechtzeitig zur Buße bereiten solle. Geistliche waren es, welche diese Bilder bestellten oder zumindest veranlaßten; sie benutzten den Volksaberglauben zu asketischer Warnung. Das beweist klar die Gestalt des Predigers auf der Kanzel am Eingang so vieler Totentänze; gleichsam zur Illustrierung seines Sermons zeigt er auf den folgenden Reigen. Adam und Eva am Baum des Paradieses, oder Christi Kreuzestod, oder der offene Höllenrachen weisen bei manchen Bildern noch deutlicher auf solchen paränetischen Zweck hin.

Der Gedanke des „Totentanzes" erhält also einen äußeren bildlichen Körper in jener Zeit der geistigen Umwälzung, welche das Mittelalter vom 13. bis in das 14. Jahrhundert durchwühlt und eine scharfe Trennung zweier Epochen bedeutet. Im religiösen Kult, in der künstlerischen Gestaltung geht jetzt, oft recht jäh und unvermittelt, gebundene Form, Feierlichkeit und Monumentalität über zur inneren Erschütterung, zur Vergegenwärtigung der religiösen Schau, zur schreckbaren Sichtbarmachung seelischer Visionen. In allen schöpferischen Vorstellungen vollzieht sich diese Entwicklung parallel, wenn auch in verschiedenem Tempo. Auch die Totentänze ordnen sich diesem Gang ein. In zwei Gestaltungsarten spiegelt sich das wider: der feierlich geschrittene Reigen fällt in die romanische Periode zurück; der gellend gesprungene nimmt in der beginnenden neuen Stilauffassung das Motiv wieder auf.

Den ältesten Typus der Totentanzbilder vertritt als frühest erhaltenes Gemälde die Darstellung an der Abtei- 
kirche der kleinen südfranzösischen Stadt La ChaiseDieu in der Auvergne, welche nach der Tracht der Lebenden aus der Zeit von 1400 bis 1410 stammt. Der Tanz der Toten ist besonders deutlich ausgeprägt; ein Leichnam z. B. wird durch die Brüste als der eines Weibes gekennzeichnet. Kunstlos, ohne Gliederung, ohne bestimmte Reihenfolge sind Tote und Lebende aneinandergereiht. Demselben Typus gehört der Toten$\operatorname{tanz}$ in der Marienkirche zu Berlin an, welcher um die Mitte des 15. Jahrhunderts entstanden ist und bereits eine Gruppierung erwägt: Christus am Kreuz als Zentralpunkt, von dem aus die Toten mit den geistlichen und den weltlichen Vertretern der Menschen je nach rechts und nach links hin sich fortbewegen. Wie zäh sich die feierliche Form erhält, beweist schließlich noch das Bild am Leichenhaus des Friedhofes zu Metniz in Kärnten, aus dem Ende des 15. Jahrhunderts; schon scheint ein leichter Humor überlegen mit dem Volksaberglauben zu spielen. Allen Darstellungen dieses feierlichen Reigens, eben des höfischen Tanzes, welcher gemessen nach dem Takte der Begleitmusik geschritten wurde, ist noch eins gemeinsam: immer steht am Anfang der Geistliche auf der Kanzel, und der Tanz ist die Nutzanwendung seiner Predigt.

Einen anderen Charakter weist die zweite Reihe der Totentanzbilder auf, welche mit dem 15. Jahrhundert, nach den vorhandenen Denkmälern, einsetzt. Der Tanz ist jetzt weit bewegter; die Toten schreiten nicht mehr feierlich daher, sondern setzen zu oft grotesken Sprüngen an. Und die Gegenwehr der Lebenden ist verzweifelter, 
heftiger an Gebärden und Mienen. Die Tanzkunst ist eben auch, im Geiste Neitharts von Reuenthal, entartet und verwildert. Die Pariser Danse macabre, welche 1425 auf die Kirchhofsmauer des Klosters Aux Innocents gemalt ward, gehörte offenbar diesem Typus an; wir besitzen von ihr allerdings nur noch die Holzschnittwiedergabe des Guyot Marchant vom Jahre 1485, während das Original schon vor 1532 zerstört wurde. Der Reigen ist recht lebhaft, und die Toten beschäftigen sich individuell, intensiv mit ihren Opfern; sie sind zu lebendigen Leichnamen geworden, die wie Menschen sich gebärden. Äußere Gliederung gab die Architektur: durch Arkaden wird hindurchgetanzt; je ein Lebender ist von solch einem Bogen eingeschlossen. Aus der Hauptstadt wanderte diese Gestaltung auf das Land hinaus; unter anderen finden wir zu Kermaria in der Bretagne eine handwerksmäßige Nachahmung, welche die Arkaden als äußere Gliederung beibehält, aber sonst sich unbeholfen bemüht, die Sprünge der Toten zu verbildlichen. Der Einfluß der französischen Bilder erstreckte sich noch weiter, bis nach England, bis nach Flandern. Vielleicht von Brügge aus gelangte die Kopie eines solchen Totentanzgemäldes nach Lübeck in die Marienkirche, oder ein niederländischcr Maler, welcher das heimatliche Bild kannte, fertigte eine Wiederholung in der Ostseestadt an. Nur handschriftlich ist das Jahr 1463 für diesen vielleicht, wegen seiner Verse, berühmtesten Totentanz als Entstehungsdatum überliefert. Die Tracht der dargestellten Menschen widerspricht dieser Ansetzung jedenfalls nicht. Hier ist die Tanzbewegung 
der Toten noch übermütiger und derber gehalten. Und auch die bekannten beiden Baseler Totentänze, zu GroßBasel im Dominikanerkonvent und zu Klingenthal(KleinBasel) im Dominikanerinnenkloster, die beide ungefähr um 1470 gemalt sind, zeigen diese Auffassung. Wie lebendig die Vorstellung vom Tanze der Toten noch war, lehrt die erste Gruppe des Groß-Baseler Bildes: Um den Prediger scharen sich die Vertreter der Stände, während aus dem daneben befindlichen Beinhaus die Toten mit Musikinstrumenten heraussteigen, um den furchtbaren Reigen zu beginnen. Und das Gleiche erkennen wir eine Generation später auf einem Holzschnitt Wolgemuts in der „Weltchronik“ des fleißigen Humanisten Hartmann Schedel: Drei Tote wissen sich vor Lustigkeit kaum zu lassen und tanzen übermütig nach dem Klang des klarinettenblasenden Kameraden um einen fünften herum, der im Begriff ist, sich aus dem Grabe zu erheben und gleichfalls in den tollen Reigen einzuspringen. Beruhigter als dieses Bild, wenn auch immer noch lebhaft genug, ist schließlich ein Venetianischer Holzschnitt von etwa 1500; auch er wird durch die offenen Gräber als Tanz der Toten mit den Lebenden gekennzeichnet.

Als um die Mitte des 15. Jahrhunderts die Totentanzbilder allgemein bekannt geworden waren, stellte man sie in Handschriften und Blockbüchern mit Versen zusammen, da ihr Inhalt dem damals neu erwachten starken religiösen Drang des deutschen Volkes willig entgegenkam. Für diese Art der Veröffentlichung konnte man indes den langen Zug der Toten und Lebenden 
nicht brauchen; sondern man zerschnitt sozusagen den Reigentanz in einzelne Paare, welche man nun gesammelt, aber jedes Paar für sich gesondert, zu einem Buch ordnete. Doch immer ist es noch der Tote, welcher mit dem Lebenden sich bewegt, wie Titel (,,Der doten dantz“"), Verse und Zeichnungen dieser Bücher klar offenbaren.

Schon früh fügte man in Frankreich, dann auch in anderen Ländern nach Art der Tituli den Bildern Verse bei, in denen die Lebenden ihr Schicksal beklagten, dann auch die Toten mit Warnungen und Aufforderungen an diese sich wandten. Daneben aber erwuchs ein zweites Gedicht, in welchem nicht der Tote, der Leichnam, sondern der personifizierte Tod die Menschen zum Eintritt in seinen Tanz befiehlt. Dieses Motiv vom Tanze des Todes war genährt durch verwandte Motive aus der Mystik, so daß vielleicht dieser Text aus Deutschland seinen Ursprung nimmt. Auch der neue Dialog vom Tanz des Todes erschien bald unter manchen Bildern, ohne daß der Widerspruch zwischen Darstellung und Wort empfunden wurde.

Doch die Trennung des Reigens in einzelne Paare von je einem Lebenden und einem Toten, welche unter äußerem Zwang in den Blockbüchern vorgenommen wurde, mußte die Auffassung verstärken, daß es sich bei dem Skelett um den personifizierten Tod handle. Holbein d. J. zieht zum erstenmal die künstlerischen Konsequenzen daraus. Er, der in humanistischer Luft aufgewachsen war, geht von der antiken Vorstellung des persönlichen Todes aus, welcher alles ohne Unterschied dahinrafft, und gibt dementsprechend einzelne 
Bilder, auf denen der Tod den jeweiligen menschlichen Standesvertreter mitten aus seiner Beschäftigung herausreißt. Auch bei ihm halten doppelte Skelette noch die Erinnerung an die Uranschauung vom Tanz der Toten fest. Sonst ist der Tanz fast ganz verschwunden; nur ein Musikinstrument in der Hand des Todes erinnert manchmal daran. In dieser Umbiegung und Wandlung des Motivs spricht sich aber auch eine gänzlich veränderte Grundstimmung aus, der Individualismus des Renaissancemenschen, welcher dem kollektivistischen Mittelalter gegenübertritt und es ablöst.

Holbeins Auffassung ist herrschend geblieben bis heute; sie hat die vielen Totentänze allenthalben beeinflußt. Genau wie Holbein den Tod handelnd in das Leben seiner Gegenwart hineinstellte, tun es auch die Späteren. Sowohl die mehr oder weniger geschickten Kopisten (wie im Bischofspalast zu Chur oder in der Handschrift zu Donaueschingen) als auch die selbständigeren Nachahmer, besonders der Barock- und Rokokozeit (Füssen, Erfurt, Chodowiecki), als auch die eigenschaffenden Künstler des 19. Jahrhunderts und der Gegenwart. In bald humorvollen, bald ernsten Zeichnungen mahnt z. B. bei Pocci der Tod. Auf Rethels Holzschnitten agitiert der Tod für die Revolution, er geigt auf dem grausigen Maskenball der Pest zum Tanz, er wallt als ernster, friedebringender Pilger durch die Lande. Auch Böcklin, von Holbeins Tuke-Porträt berührt, hörte von der letzten Saite der Todesfiedel den Tod schwirren. Das gewaltige Erlebnis des Weltkrieges hat mehr denn je gerade das Motiv des Totentanzes 
den Künstlern und Dichtern wieder vor die Seele gerückt. Hier taucht vielfach die Uranschauung wieder empor, daß das Heer der Toten aus den Gräbern steigt und die Lebenden in seine Reihen zwingt. Damit ist der alte Ausgangspunkt wieder erreicht, der Kreis geschlossen, in welchem Mensch und Mensch sich begegnen.

Ein religiöses Motiv, herausgeboren aus der gläubigen Scheu vor dunklen Gewalten, gewinnt zu paränetischen und didaktischen Zwecken bewußte, sichtbare Gestalt und erhält lyrische Untermalung. Es gelangt weiter zu lyrisch-dramatischer Selbständigkeit und kehrt zur ursprünglichen, organischen Verbildlichung schließlich wieder zurück, als eine Zeit kommt, in welcher die dynamischen Kräfte der Menschheit von neuem entbunden werden und das Übersinnliche seine alte Kraft wiedererlangt. Und der lateinischen Hymne des St. Galler Mönches reichen die Verse Rainer Maria Rilkes, die Kette schließend, die Hand:

\author{
Der Tod ist groß. \\ Wir sind die Seinen \\ lachenden Munds. \\ Wenn wir uns mitten im Leben meinen, \\ wagt er $\mathrm{zu}$ weinen \\ mitten in uns.
}

Die wissenschaftliche Begrundung fur das hier knapp Vorgetragene (nur das Bild von Kermaria hahe ich jetzt später angesetzt), besonders fur die geistesgeschichtliche Einstellung von Bild und Text der Totentänze und fur die Entstehung der Verse, habe ich in meinem Buche: „Die Totentănze des Mittelalters" (Munchen 1922, Horst Stobbe) gegeben; dort ist anch die wichtigste Literatur verzeichnet. 
$\begin{array}{llllllllllll}A & B & B & I & L & D & U & N & G & E & N\end{array}$ 
1. Aus dem Totentanz an der Abteikirche zu La Chaise-Dieu in der Auvergne (etwa 1400-1410)

2. Aus dem Totentanz in der Marienkirche zu Berlin (Mitte des 15. Jahrhunderts)

3. Aus dem Totentanz vom Beinbaus zu Metniz in Kärnten (etwa r 500)

4. Aus der Pariser „Danse macabre" nach dem Holzschnitt des Guyot Marchant (1485)

5. Totentanz zu Kermaria in der Bretagne (etwa I 470 - I480)

6. Aus dem Totentanz in der Marienkirche zu Lubeck ( 1463 )

7. Aus den Totentänzen zu Groß-und Klein-Basel (etwa I 470)

8. Zeichnung aus der Munchener Handschrift clm. 394I (Zweite Halfte des I 5. Jahrbunderts)

9. Holzschnitt aus dem „Buch der Chroniken und Geschichten“ des Hartmann Schedel (1493)

10. Miniatur aus der Wolfenbuttler Handsclurift A Aug. fol. Nr. 1563 (elwa I 520 )

I I. Holzschnitt aus dem Heidelberger Blockbuch, cod. pal. germ. 438 (Mitte des I 5. Jahrhunderts)

12. Aus dem Holzschnittbuch „Der doten dantz" (2. Hälfte des I5. Jabrhunderts)

I3. Holzschnitte aus den ,Icones mortis" von Hans Holbein d. J. ( I 538)

14. Miniatur aus der Donaueschinger Handschrift Nr. I23 (Mitte des 16. Jahrhunderts)

15. Aus dem Totentanz des Jakob Hiebeler in der St. Annakapelle zu Fussen (1595-1600)

16. Kupfer aus Abrabam a St. Clara: ,Todten-Capelle" ( 7 Io)

17. Totentanz von P. V. Borromini. Bergamo, Chiesa di S. Grata (etwa 18ro)

18. Franz Graf von Pocci (1807-1876), Schattenbild

19. Frans Masereel, Mobilmachung (I919)

20. Arnold Böcklin, Selbstbildnis mit Tod (1872) 


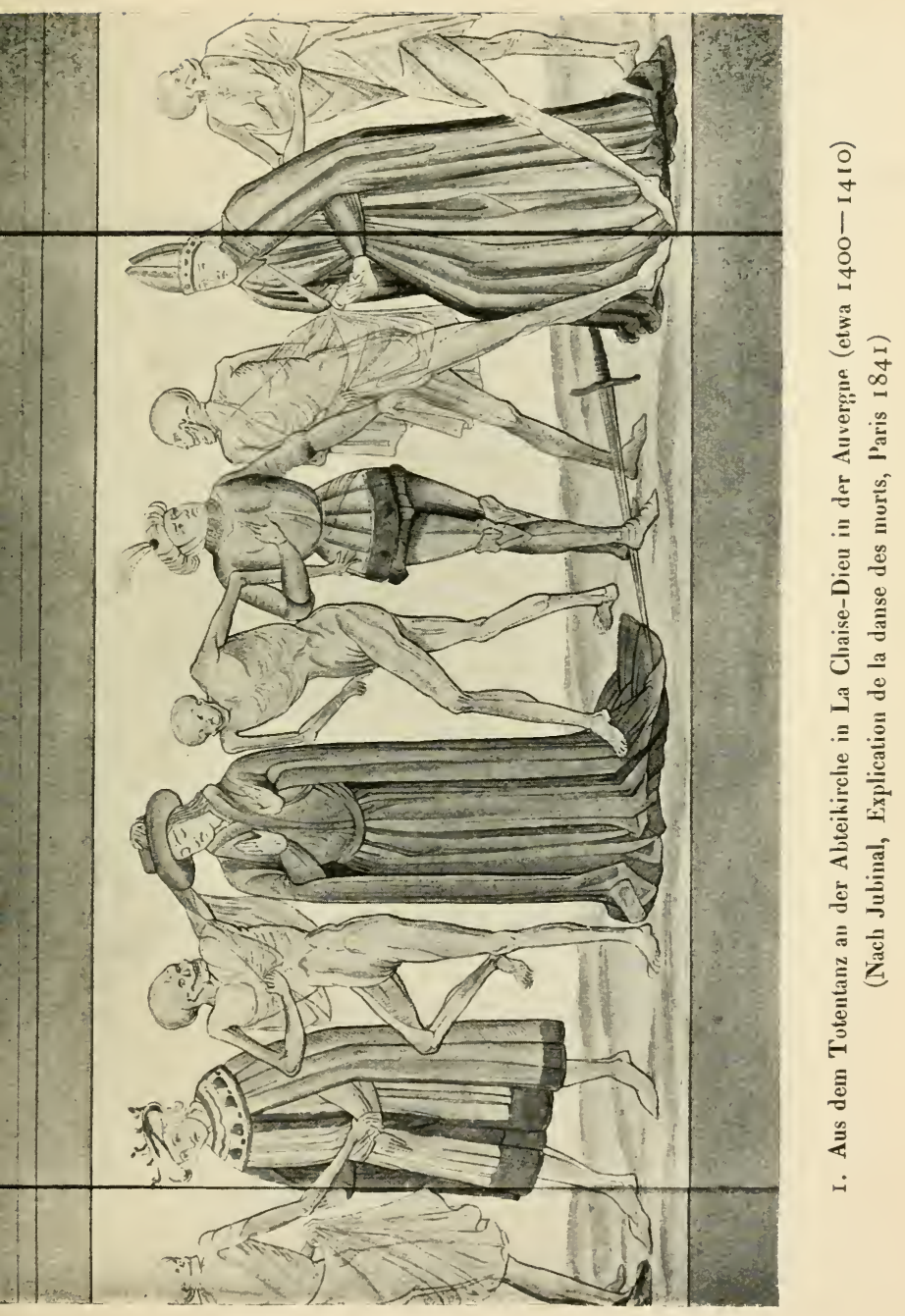




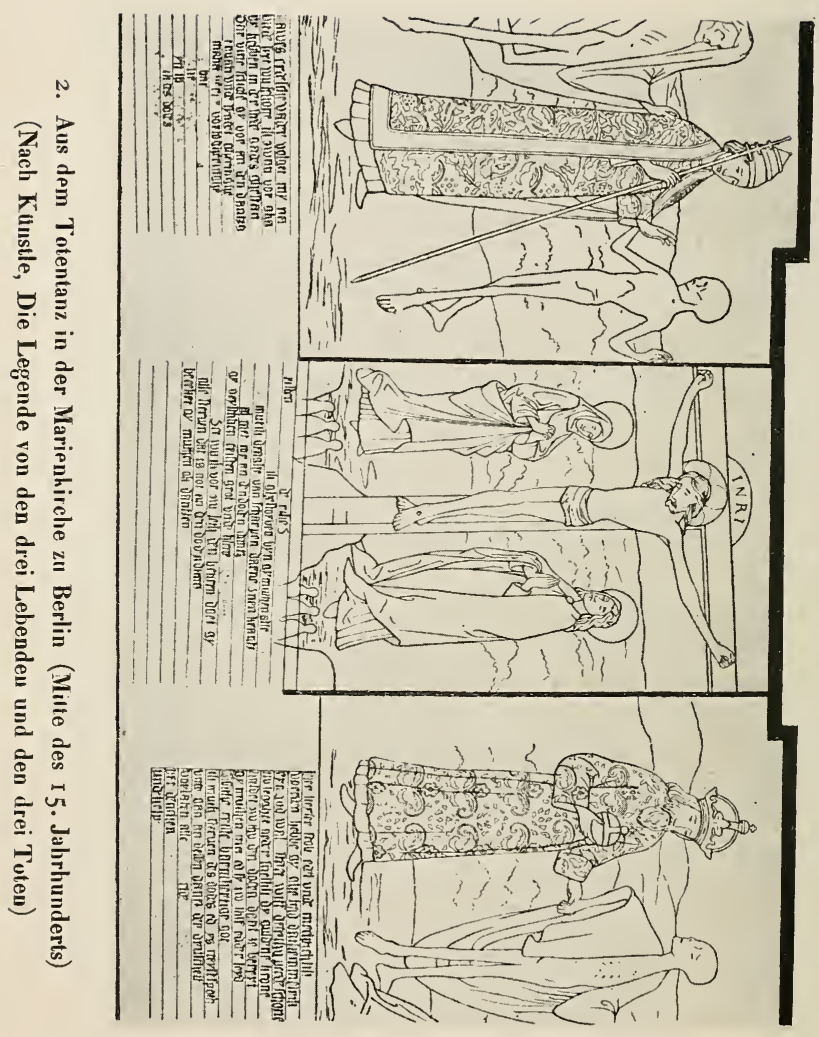




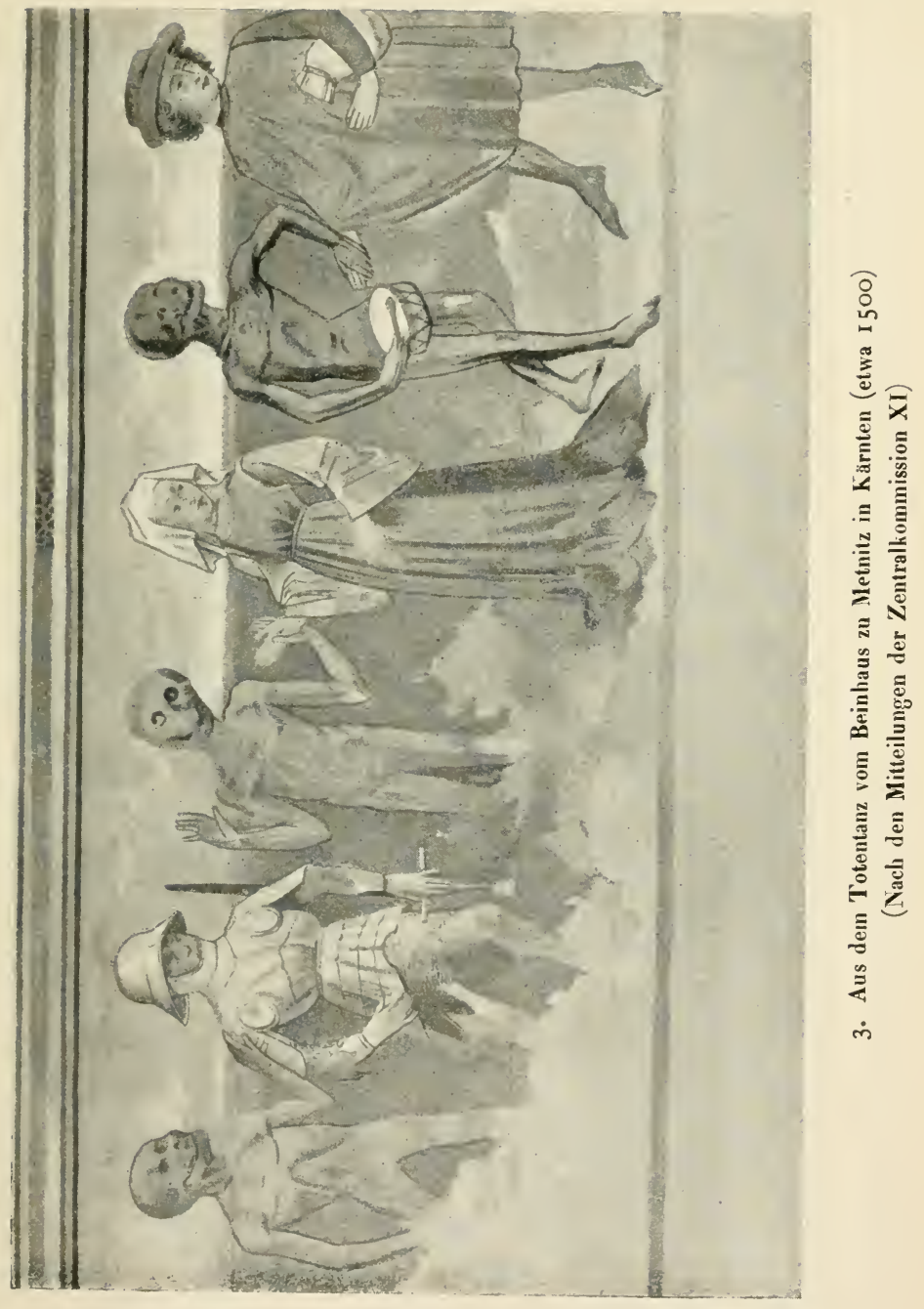

B. D. K. 47 


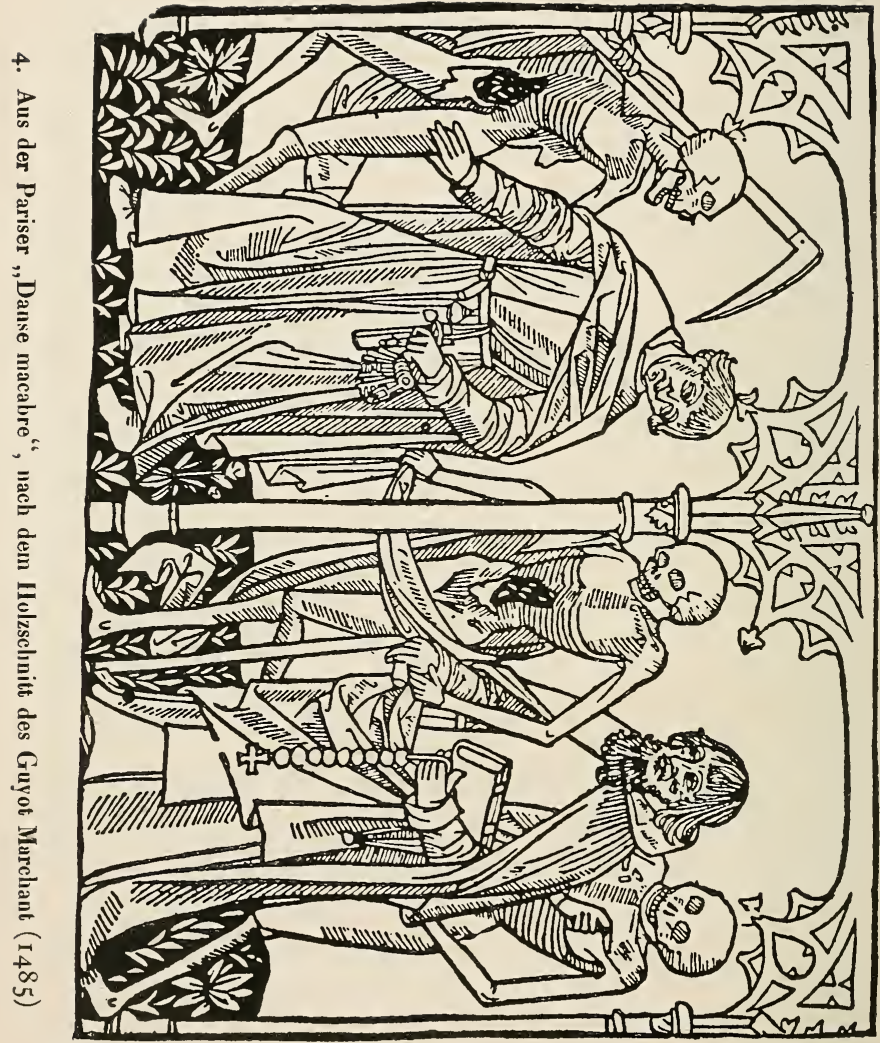




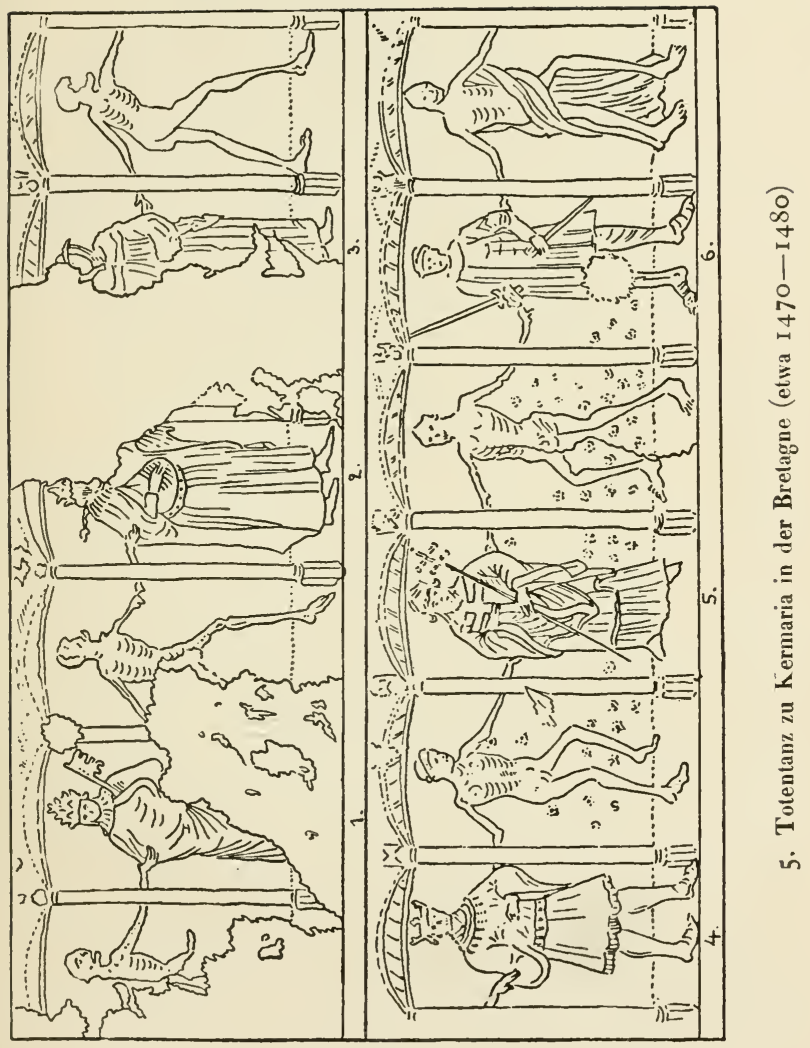




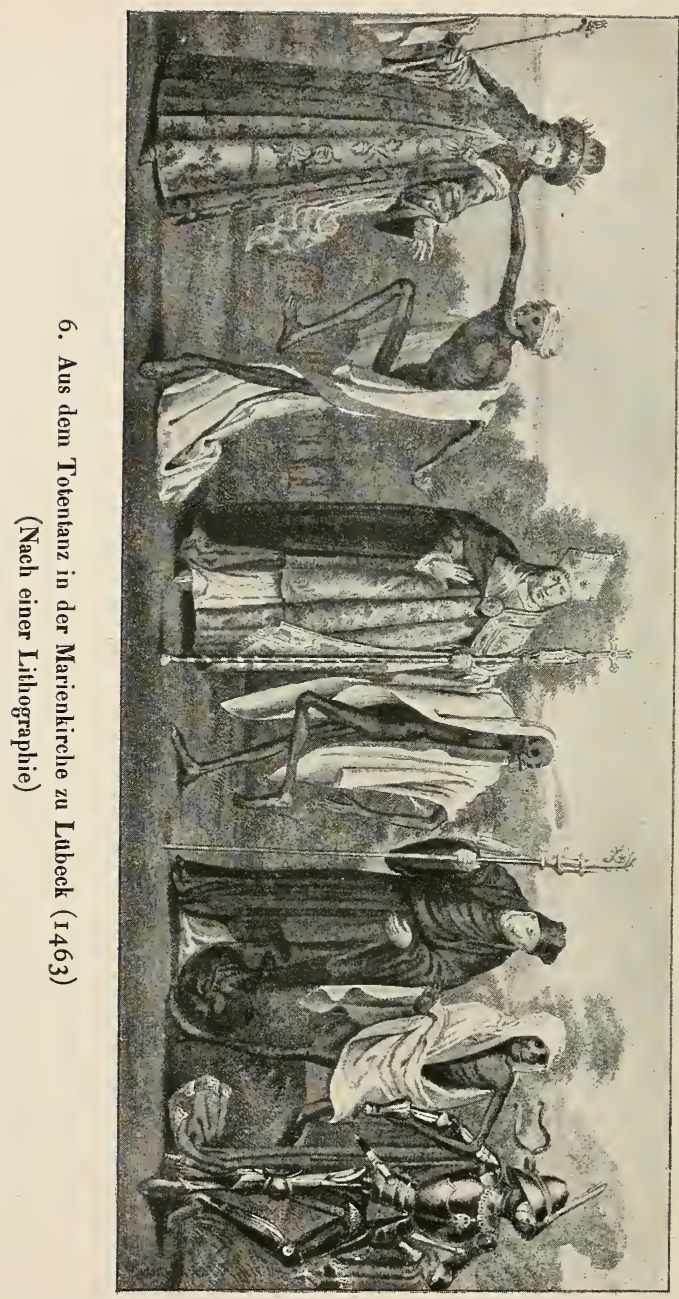




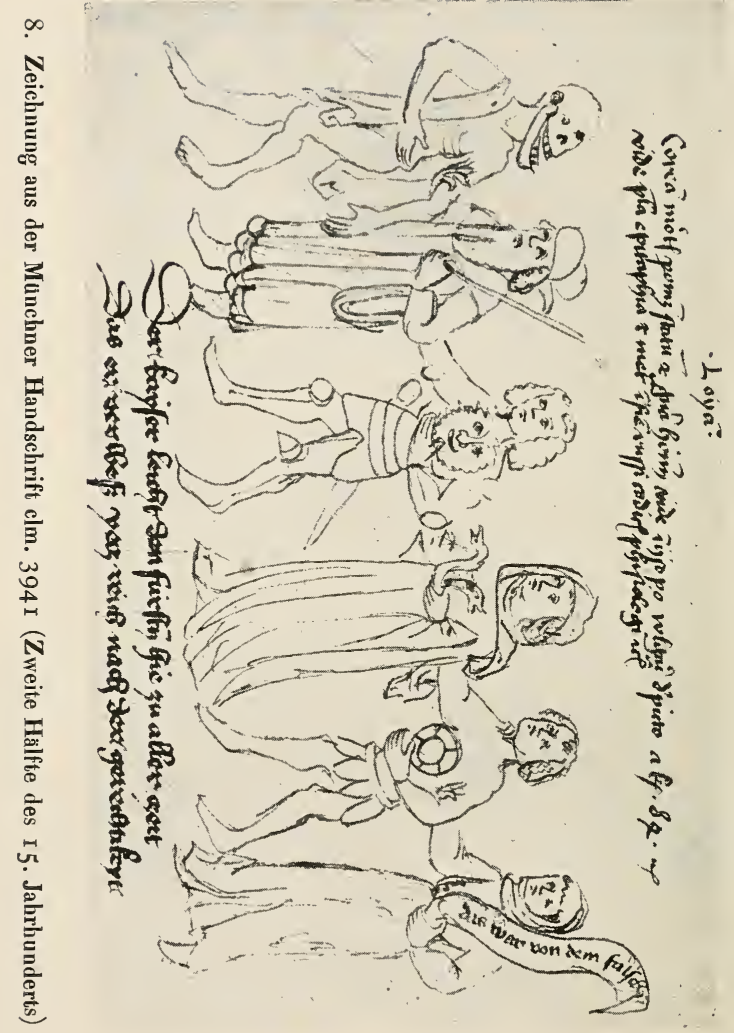




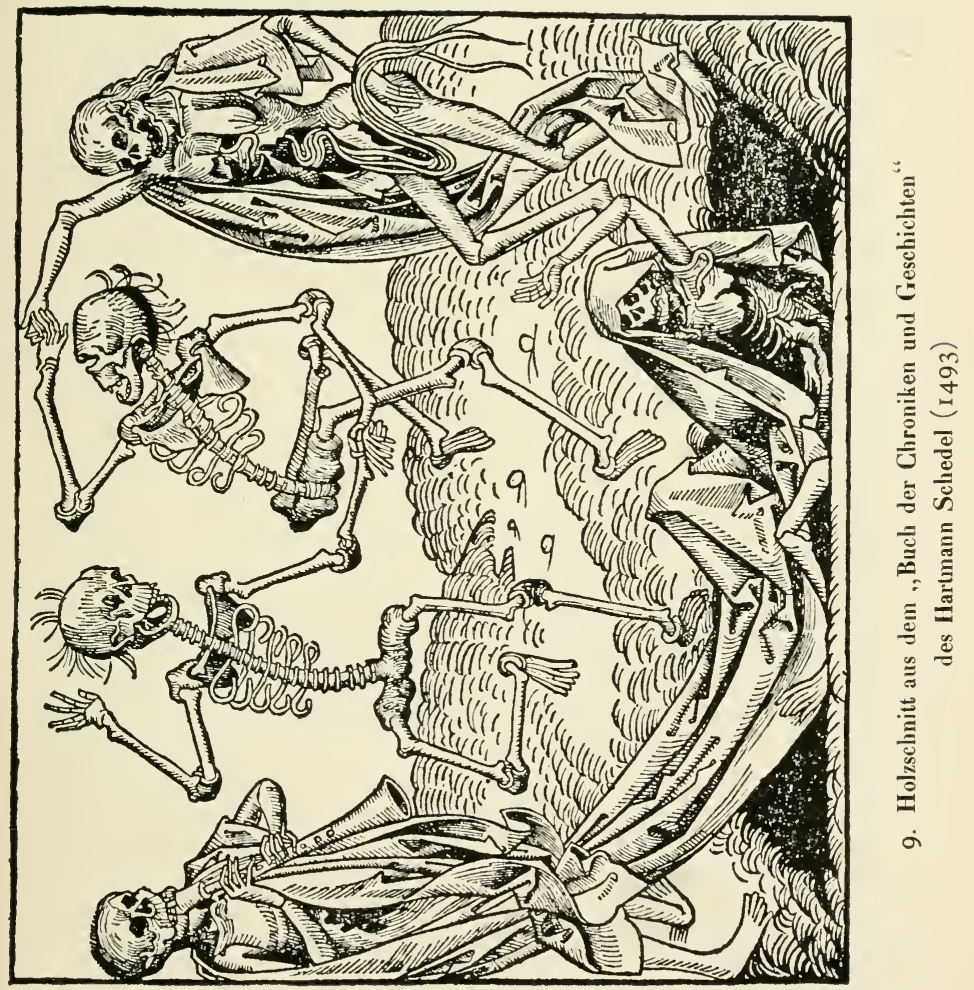




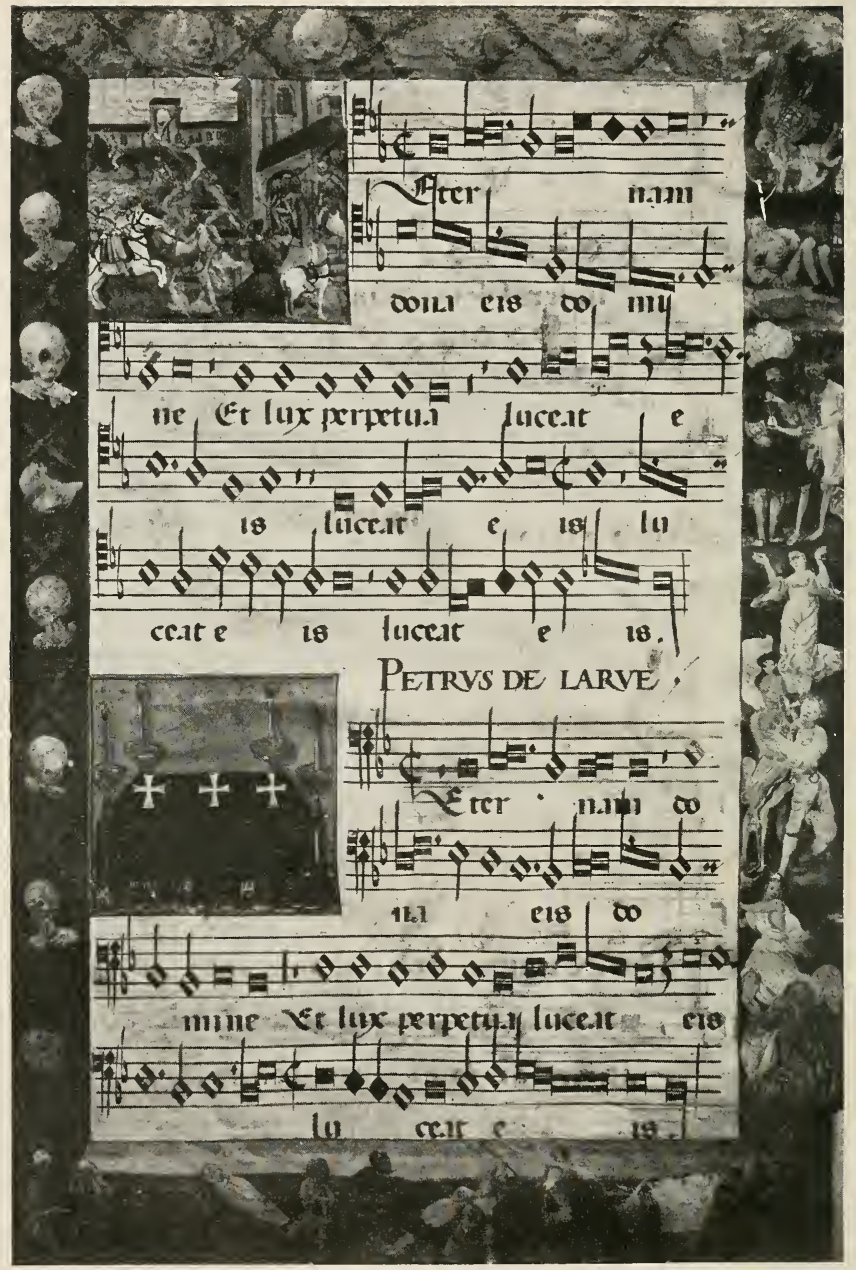

IO. Miniatur aus der Wolfenbüttler Handschrift A. Aug. fol. Nr. I 563 (etwa I 520) 


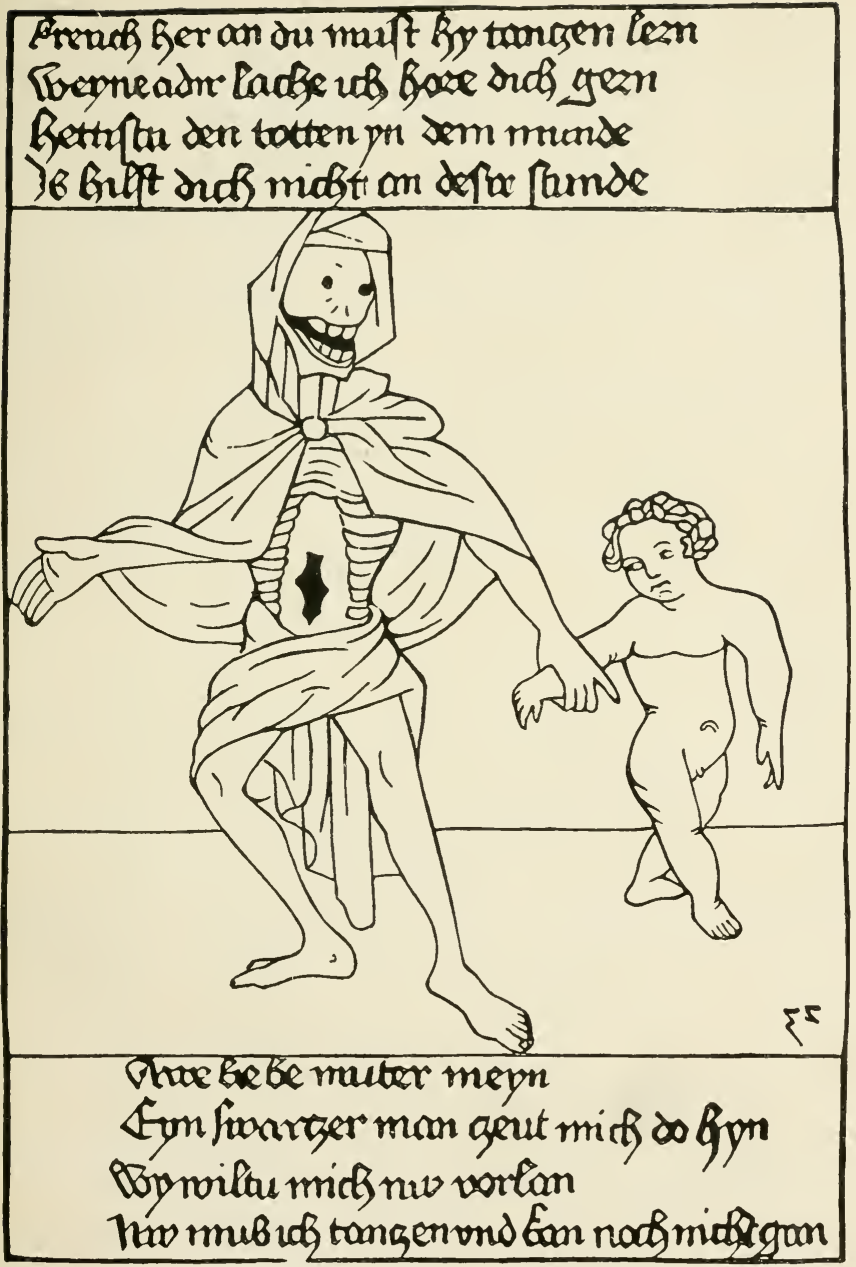

I I. Holzschnitt aus dem IIeidelberger Blockbuch, cod. pal. germ. $43^{8}$

(Mitte des I 5. Jahrhunderts) 

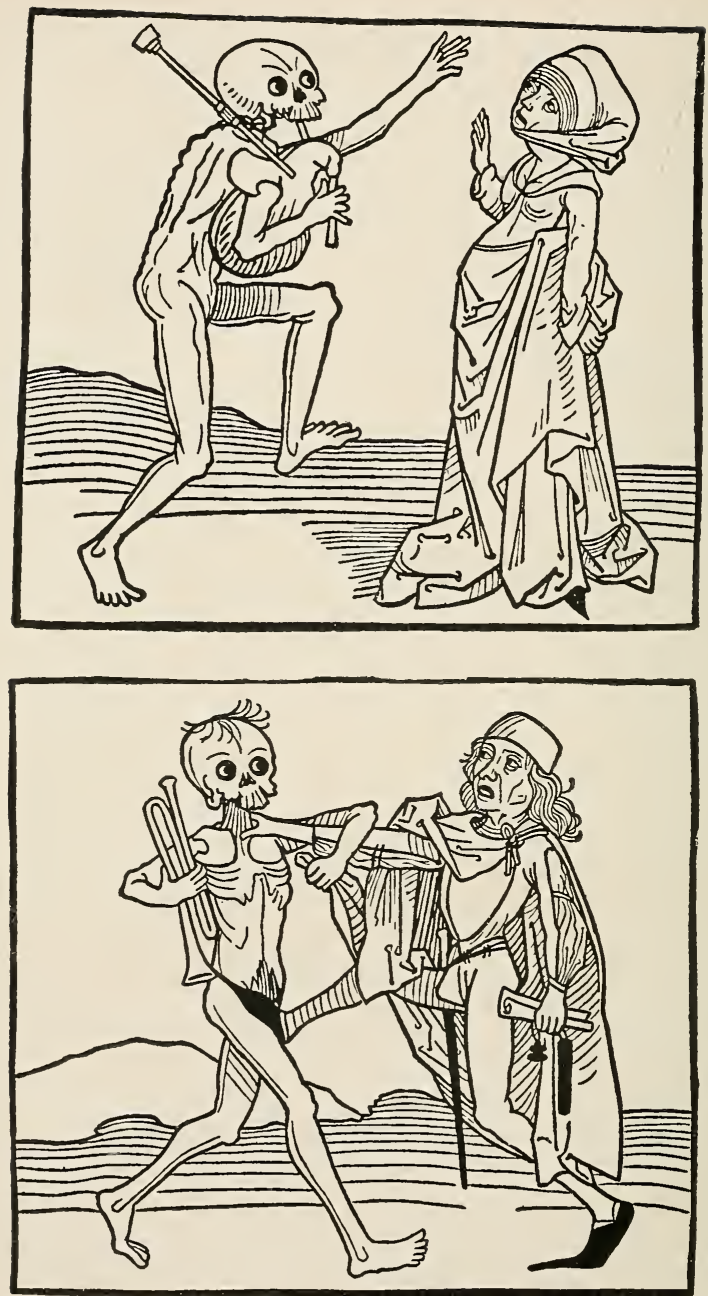

12. Aus ,Der doten dantz mit Figuren“" Heidelberg (Zweite Hälfte des I 5. Jahrhunderts) 


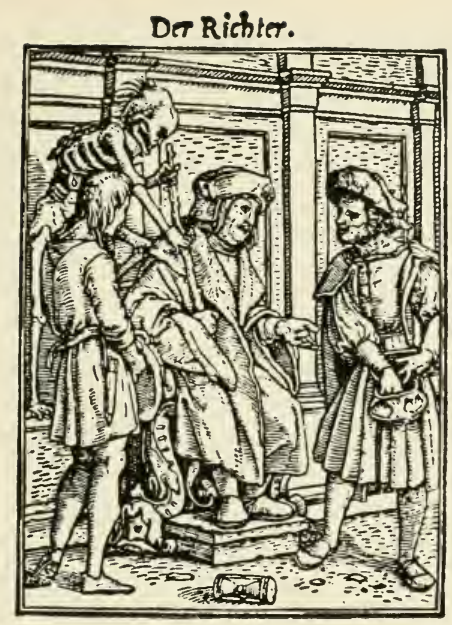

\section{Die Edelfraw.}

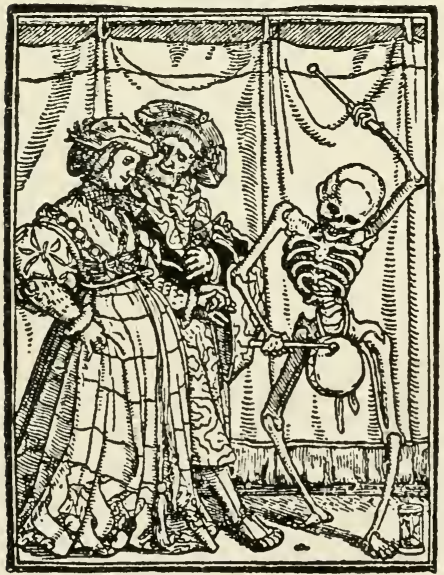

I 3. Holzschnitte aus den ,Icones mortis" von Hans Holbein d. J. ( 1538 ) 


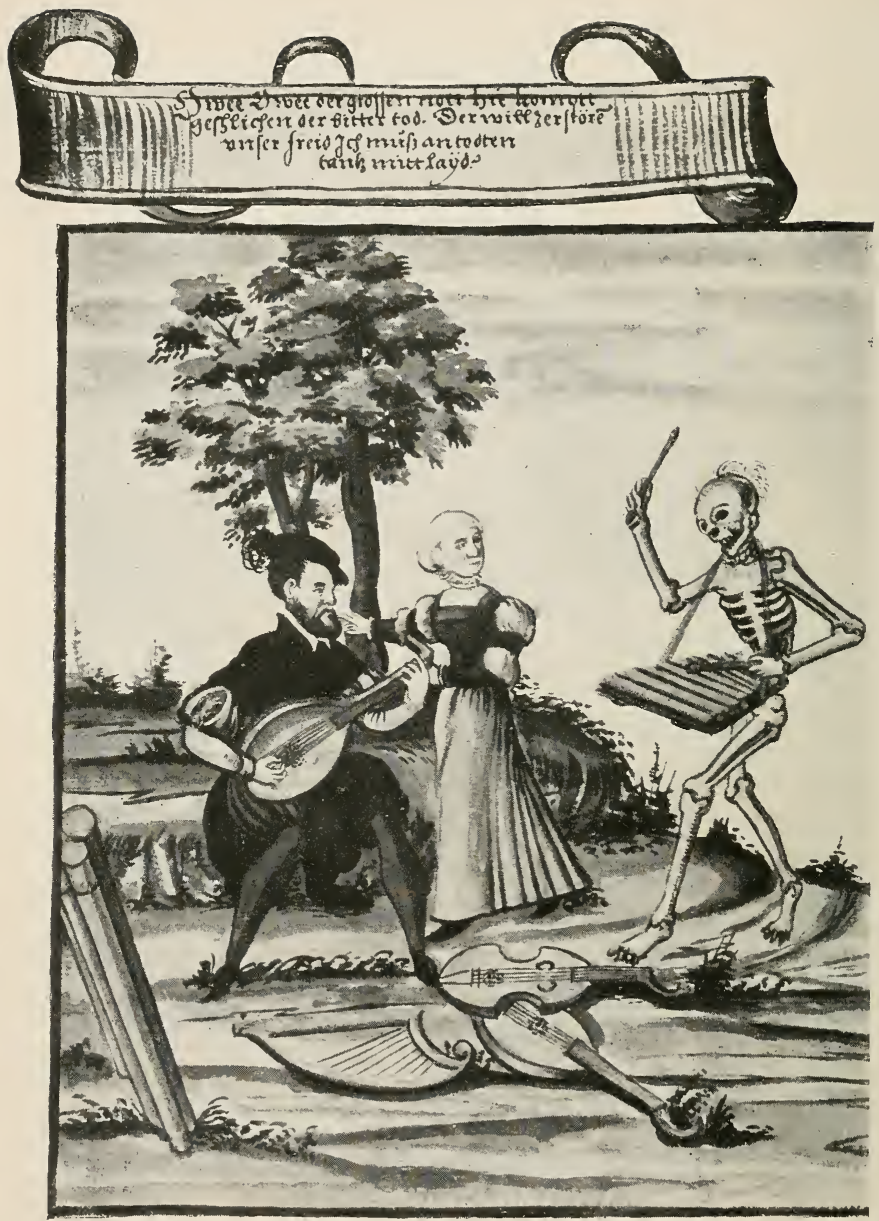

I 4. Miniatur aus der Donaueschinger Handschrift Nr. I 23

(Mitte des I6. Jahrhunderts) 


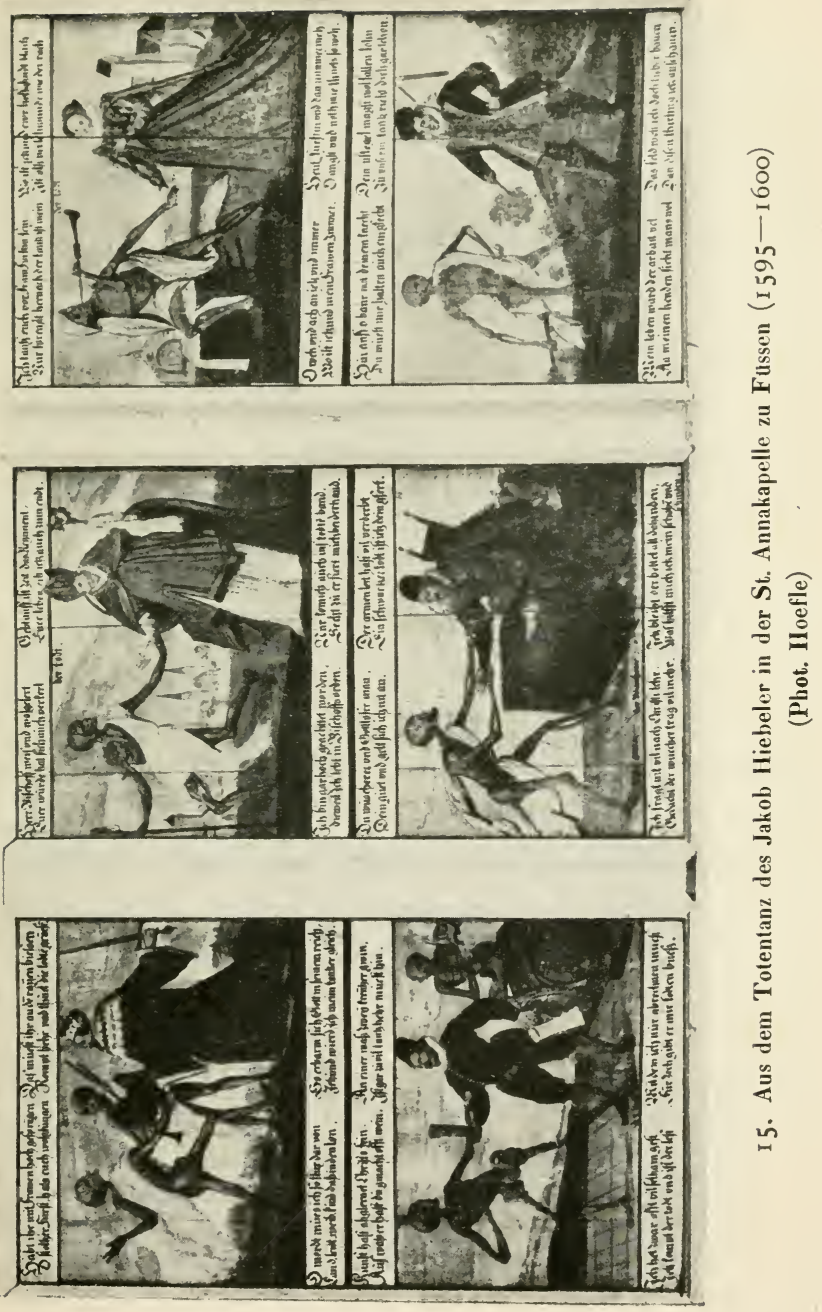




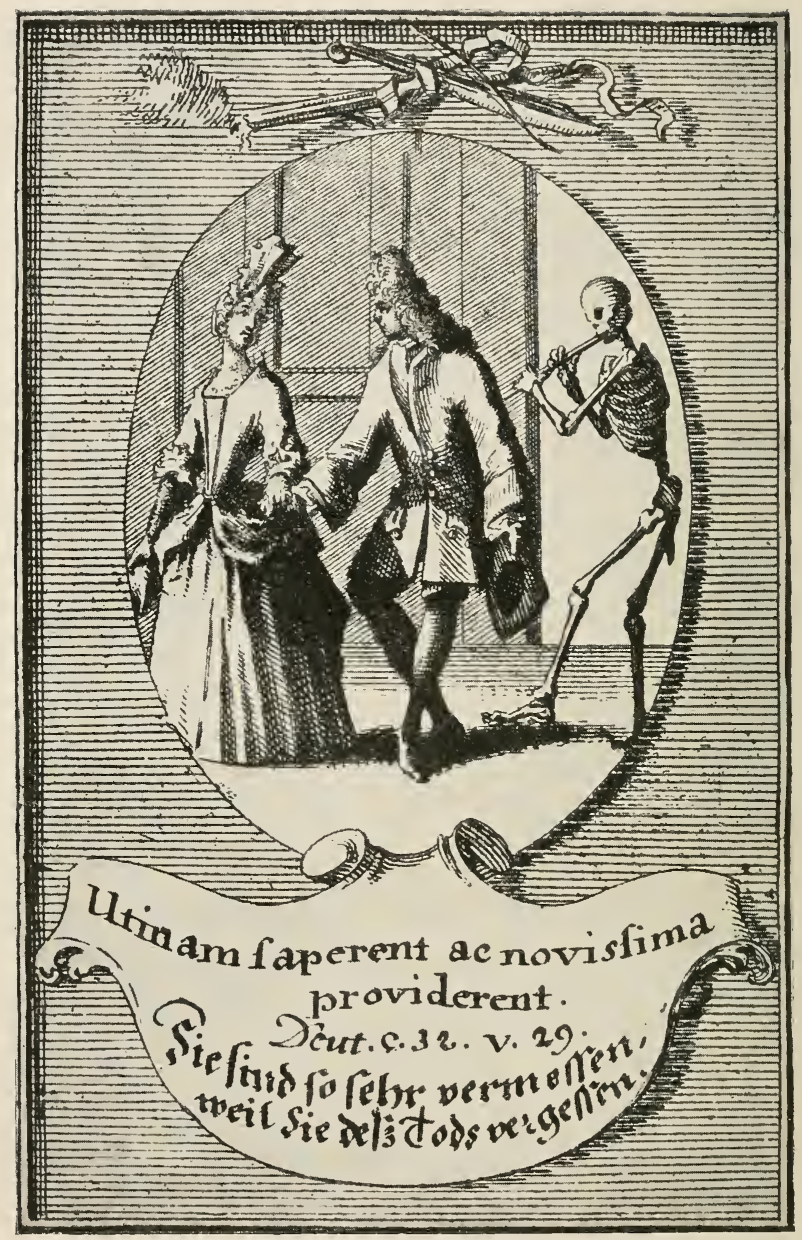

I6. Kupfer aus Abraham a Sancta Clara, ,Todten-Capelle“ ( 7 ro) 


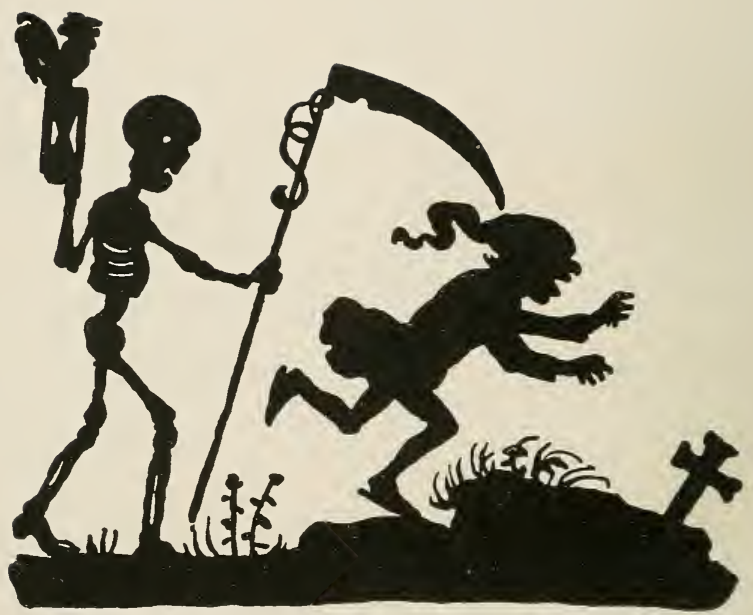

I8. Franz Graf v. Pocci (I807-I876), Schattenbild 


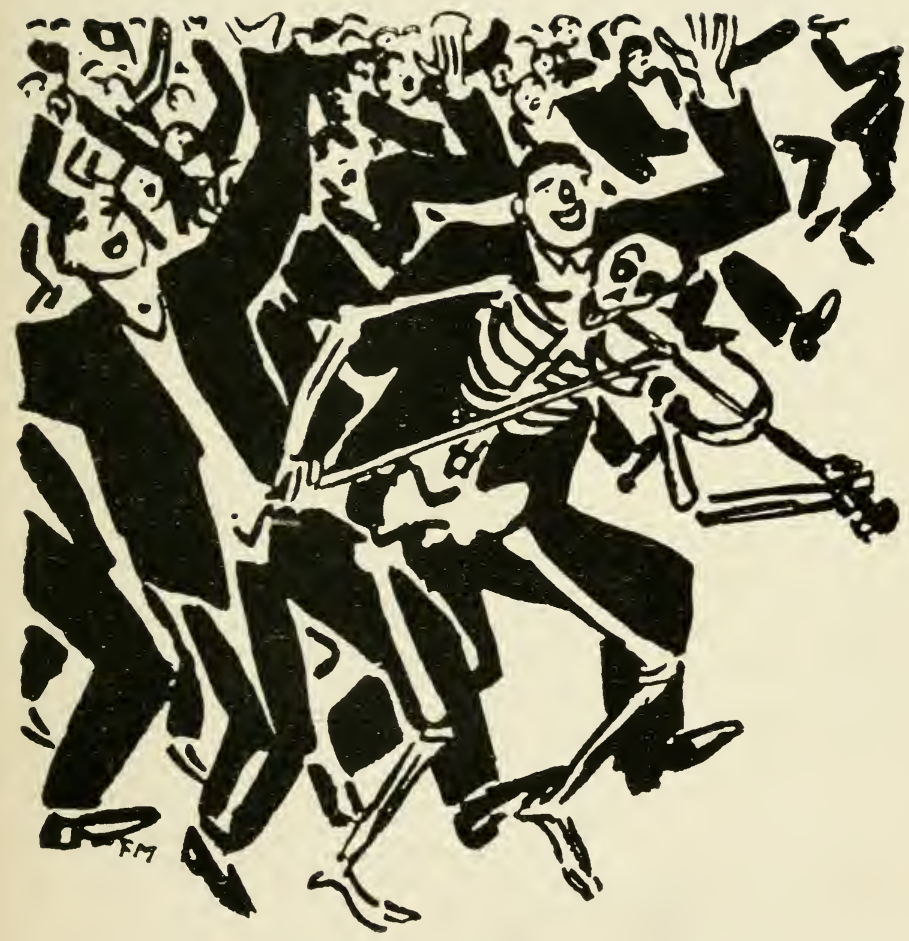

I 9. Frans Masereel, Mobilmackung (1 919) 


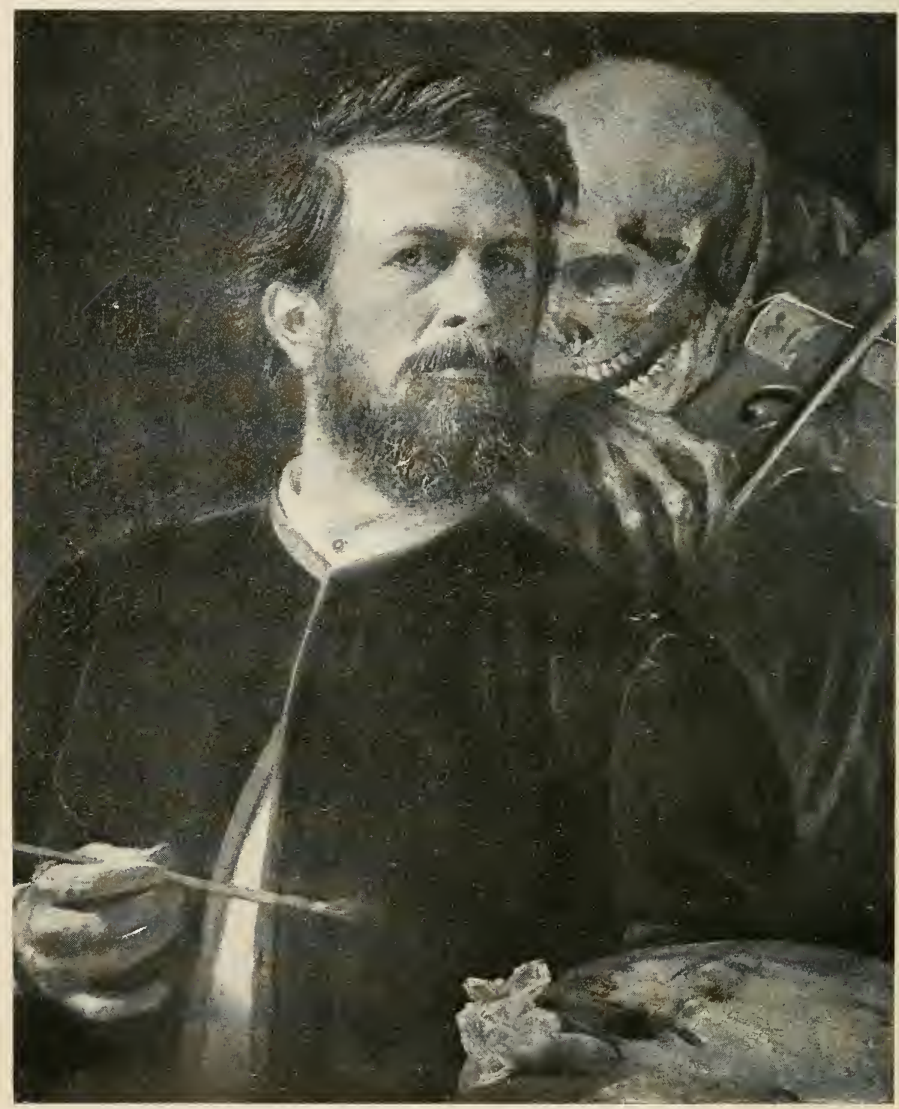

20. Arnold Böchlin, Selbstbildnis mit Tod (I872)

(Mit Genehmigung der Photographischen Union, Müchen) 


SMITHSONIAN INSTITUTION LIBRARIES

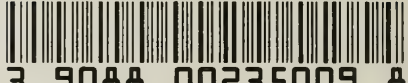

39088 00235009 8 chm N7720.A1S78

Die Totent?anze / 